\title{
Analysis of the dynamic relationship between immune profiles and the clinical features of patients with COVID-19
}

\author{
Pingping Ren ${ }^{1,2,3,4,5 \#}$, Chaohong Zhu ${ }^{1,2,3,4,5 \#}$, Yongchun $\mathrm{He}^{1,2,3,4,5}$, Hong Jiang ${ }^{1,2,3,4,5}$, Jianghua Chen ${ }^{1,2,3,4,5} \wedge$ \\ ${ }^{1}$ Kidney Disease Center, the First Affiliated Hospital, College of Medicine, Zhejiang University, Hangzhou, China; ${ }^{2}$ Key Laboratory of Kidney \\ Disease Prevention and Control Technology, Zhejiang Province, Hangzhou, China; ${ }^{3}$ National Key Clinical Department of Kidney Diseases, \\ Hangzhou, China; ${ }^{4}$ Institute of Nephrology, Zhejiang University, Hangzhou, China; ${ }^{5}$ The Third Grade Laboratory under the National State, \\ Administration of Traditional Chinese Medicine, Hangzhou, China \\ Contributions: (I) Conception and design: H Jiang, J Chen; (II) Administrative support: H Jiang, J Chen; (III) Provision of study materials or patients: \\ P Ren; (IV) Collection and assembly of data: P Ren, C Zhu; (V) Data analysis and interpretation: C Zhu, Y He; (VI) Manuscript writing: All authors; \\ (VII) Final approval of manuscript: All authors. \\ "These authors contributed equally to this work. \\ Correspondence to: Jianghua Chen or Hong Jiang. Kidney Disease Center, the First Affiliated Hospital, College of Medicine, Zhejiang University, \\ Hangzhou 310003, China. Email: zjukidney@zju.edu.cn; jianghong961106@zju.edu.cn.
}

Background: The novel coronavirus disease (COVID-19) has been declared a global pandemic, with the cumulative number of confirmed cases and deaths exceeding 150 million and 3 million, respectively. Here, we examined the dynamic changes in the immune and clinical features of patients with COVID-19.

Methods: Clinical data of 98 patients with confirmed COVID-19 diagnosis were acquired from electronic medical records and curated. The data were analyzed based on the stage of the admission, deterioration, and convalescence, which included age, sex, severity, disease stages, biochemical indicators, immune cells, inflammatory cytokines, and immunoglobulins. Additionally, temporal changes in the immune response in patients undergoing continuous renal replacement therapy (CRRT) were also examined.

Results: Compared to mild stage patients, severe stage patients with COVID-19 exhibited a significant reduction in lymphocyte [23.10 (17.58-33.55) vs. 4.80 (2.95-6.50), $\mathrm{P}<0.001]$, monocyte [8.65 (7.28-10.00) vs. 3.45 (2.53-4.58), $\mathrm{P}<0.001]$, and NK cell levels [244.00 (150.50-335.00) vs. 59.00 (40.00-101.00), $\mathrm{P}<0.001$ ] but showed elevated levels of neutrophils [64.90 (56.30-73.70) vs. 90.95 (87.60-93.68), $\mathrm{P}<0.001$, inflammatory cytokines [Interleukin-10, 3.05 (1.37-3.86) vs. 5.94 (3.84-8.35), $\mathrm{P}=0.001$; and tumor necrosis factor- $\alpha, 11.50$ (6.55-26.45) vs. 12.96 (12.22-36.80), $\mathrm{P}=0.029$ ], which improved during convalescence. Besides, the number of immune cells-T lymphocytes, B lymphocytes, helper $\mathrm{T}$ cells, suppressor $\mathrm{T}$ cells, NK cells, and monocytes, except neutrophils—slowly increased in critically ill patients receiving CRRT from 0 to 3 weeks.

Conclusions: Our results indicate that the surveillance of immune cells may contribute to monitoring COVID-19 disease progression, and CRRT is a potential therapeutic strategy to regulate the immune balance in critically ill patients.

Keywords: COVID-19; immune cells; cytokines; continuous renal replacement therapy (CRRT)

Submitted Feb 20, 2021. Accepted for publication Jun 11, 2021.

doi: $10.21037 / \mathrm{atm}-21-812$

View this article at: https://dx.doi.org/10.21037/atm-21-812

^ ORCID: Jianghua Chen, 0000-0002-1805-0589; Hong Jiang, 0000-0001-7692-5745. 


\section{Introduction}

The outbreak of coronavirus disease (COVID-19), caused by severe acute respiratory syndrome coronavirus 2 (SARS$\mathrm{CoV}-2)$, has rapidly swept worldwide (1-3). Hitherto, the global coronavirus case count has exceeded 150 million, with the cumulative number of deaths surpassing 3 million, leading to a profound and constantly evolving impact on global public health security and the world economy. This novel coronavirus could infect people via droplets and aerosols (4-7); furthermore, Moghadas et al. found that most transmissions were attributable to presymptomatic and asymptomatic individuals and probably caused an unexpected outbreak, which deeply threatened the prevention and treatment of infectious diseases (8). Several studies have shown that the elderly are more prone to COVID-19, presenting with initial manifestations of fever, cough, and myalgia or fatigue $(9,10)$. Approximately $20-30 \%$ of cases need further intervention in intensive care units (ICU) due to serious complications, including acute respiratory distress syndrome, acute cardiac/renal injury, and septic shock (10-12). Currently, clinical treatment is empirically administered, consisting of symptomatic management, oxygen therapy, and antiviral drugs, with some critically ill patients needing continuous renal replacement therapy (CRRT) to help remove potential toxins and stabilize their metabolic statuses (13). Notably, the sequelae of patients with severe COVID-19 were much worse, accompanied by more severe impaired pulmonary diffusion capacities and abnormal chest imaging manifestations (14).

Evidence is mounting that the aberrant immune response was crucial in the pathogenesis of SARS-CoV-2. Several studies have reported that patients with severe COVID-19 exhibited sharply decreased counts of immune cells, including $\mathrm{T}$ cells, B cells, natural killer (NK) cells, monocytes, basophils, and eosinophils, but not neutrophils (15-19). In contrast, these patients displayed continuously increasing levels of pro-inflammatory cytokines such as interleukin (IL)-10, IL-2, IL-6, and tumor necrosis factor- $\alpha$ (TNF- $\alpha$ ) $(10,17)$. Moreover, Zhang et al. (18) found that the severity of COVID-19 correlated with increased immunoglobulin (Ig) G response. Besides, the single-cell landscape has revealed that inflammatory monocyte-derived macrophages increased in SARS-CoV-2-infected lungs, especially from patients with severe COVID-19 (20). Meanwhile, a specific subset of macrophages identified in patients with COVID-19 were probably associated with tissue fibrosis (21). Eventually, the disturbance of immunity by SARS-CoV-2 will result in damaged tissues, even causing shock or multiple organ dysfunction. From an epidemiological perspective, the coronavirus vaccine is the best method to prevent infection and restrict the COVID-19 pandemic; thus, many coronavirus vaccines have been developed and reported to be effective $(22,23)$. However, the progress and effectiveness of the vaccine seem inadequate especially considering the recently mutated coronavirus.

Given the above complications, clinicians should comprehend the status of a disease at any time, promptly prevent the deterioration of the condition, and optimize the management and treatment for patients with COVID-19. Therefore, we analyzed the dynamic temporal alterations in immune cells and multiple cytokines in the peripheral blood of patients with COVID-19 during the hospital admission, initial deterioration, and convalescent stages and examined the effect of CRRT on immune homeostasis in critically ill patients. Here, we discuss the findings of this study, elaborating the role of immune cells and factors in the progression of COVID-19 and the potential therapeutic benefits of CRRT. We present the following article in accordance with the STROBE reporting checklist (available at https://dx.doi.org/10.21037/atm-21-812).

\section{Methods}

\section{Study population}

Ninety-eight patients diagnosed with COVID-19 were recruited for this study from the First Affiliated Hospital of the College of Medicine at Zhejiang University from January 02, 2020 to March 16, 2020. The flow diagram of selecting patients with COVID-19 is shown in Figure 1. All patients enrolled in the study signed written informed consents personally or via designated surrogates. The study was conducted following the Declaration of Helsinki (as revised in 2013). The study was approved by the Clinical Research Ethics Committee of the First Affiliated Hospital, College of Medicine, Zhejiang University (No. 2020IIT195), and individual consents for this retrospective analysis were waived.

\section{Procedures}

Patient data, including clinical features (sex, age, symptoms, signs, body temperature, length of stay, chronic medical illness, comorbidities, dialysis modality), laboratory results (biochemical indicators, blood routine examination, 


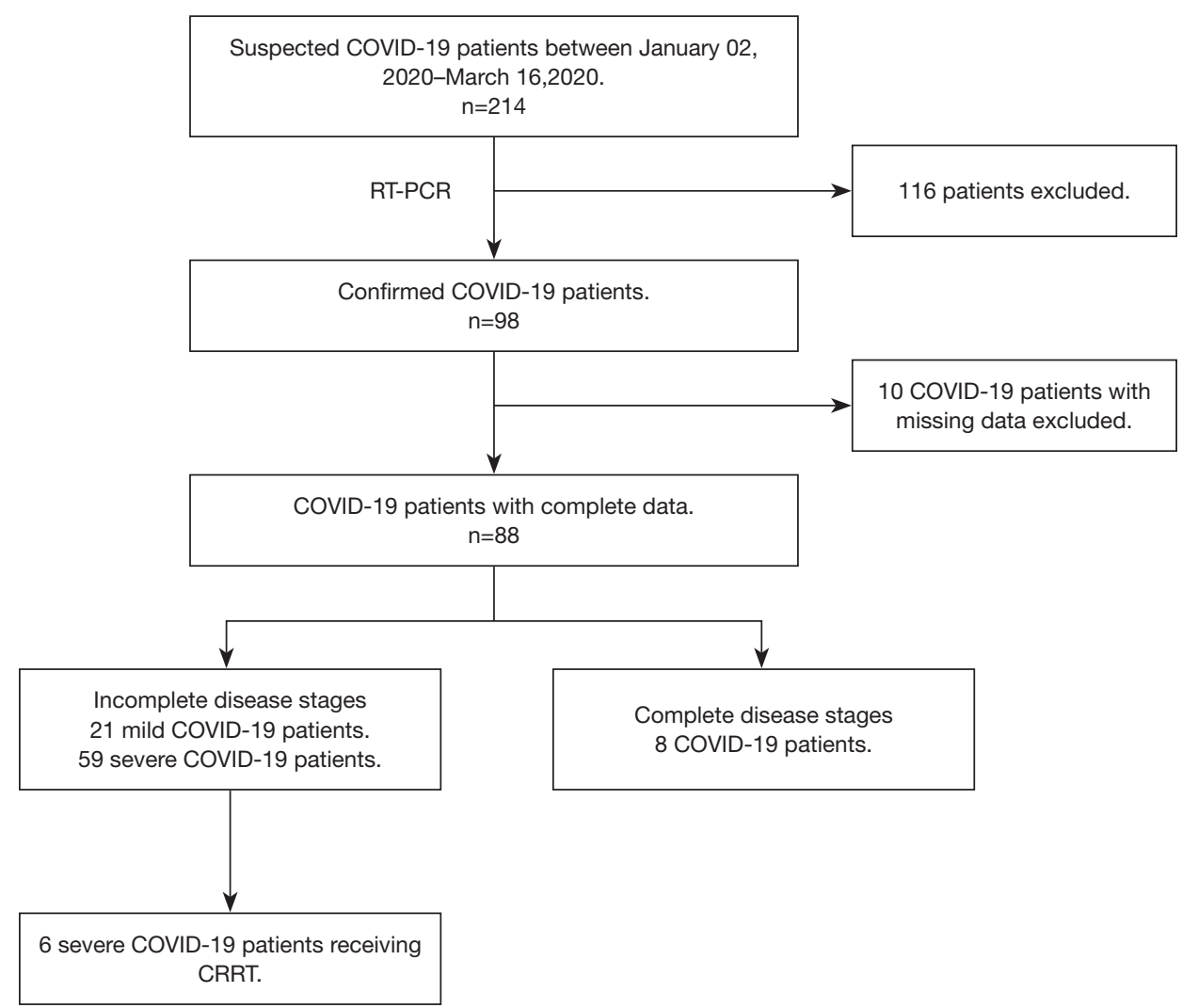

Figure 1 Selection procedure of COVID-19 patients. The diagnosis of COVID-19 was confirmed by RT-PCR assay. Incomplete disease stages represented that patients were lack of admission or deterioration stages; complete disease stages represented that patients progressed through admission, deterioration and convalescence stages during hospitalization. RT-PCR, reverse transcriptase-polymerase chain reaction.

infection-related biomarkers, inflammatory cytokines, immunoglobulins, complement proteins, immune cell subsets), treatment and outcomes were obtained from the hospital's electronic medical records. All patients underwent chest radiography or computed tomography and laboratory confirmation of SARS-CoV-2 at admission according to the WHO guidance as positive nasal and pharyngeal swab specimens by real-time reverse transcriptasepolymerase chain reaction (RT-PCR) assay. Two researchers independently reviewed the data for accuracy and communicated with patients or their family members to ascertain the epidemiological and symptom data.

\section{Classification of diseases}

Patients with COVID-19 who met any of the following criteria were diagnosed as severe patients: (I) respiratory distress with the respiratory rate $\geq 30$ breaths per minute; (II) oxygen saturation $\leq 93 \%$ at rest; (III) arterial blood oxygen partial pressure $\left(\mathrm{PaO}_{2}\right)$ /oxygen concentration $\left(\mathrm{FiO}_{2}\right)$ $\leq 300 \mathrm{mmHg}(1 \mathrm{mmHg}=0.133 \mathrm{kPa})$; (IV) significant lesion progression $>50 \%$ within $24-48 \mathrm{~h}$ on chest imaging; (V) respiratory failure requiring mechanical ventilation, shock, and ICU admission required for restoring combined organ function.

\section{Statistical analysis}

All variables were expressed as median with interquartile range (IQR). Individuals whose data could not be found were excluded. $T$-tests were used to compare means for normally distributed continuous variables; otherwise, the Mann-Whitney $\mathrm{U}$ test was applied. Line charts were drawn to display the dynamic change of variables. Proportions of categorical variables were compared using the $\chi^{2}$ test or Fisher's exact test. All statistical analyses were performed using SPSS (Statistical Package for the Social Sciences) version 25.0 (SPSS Inc.). Two-sided P values of less than 
0.05 were considered statistically significant.

\section{Results}

\section{Demographic and clinical characteristics of patients with mild and severe COVID-19}

Among the 98 patients with COVID-19, 10 were rejected for lack of integrity regarding their clinical data, and 8 were enrolled to be dynamically analyzed. Ultimately, 21 patients whose clinical data were collected on admission were diagnosed with mild conditions and did not deteriorate during hospitalization. Conversely, 59 patients were diagnosed with severe conditions requiring hospitalization. For these patients, additional clinical data were collected during convalescence.

Compared to patients with mild conditions, patients with severe conditions were remarkably older [median age, 61 (IQR, 51-70) years vs. 50 (IQR, 35-61) years; $\mathrm{P}=0.002]$. The proportion of men among patients was not significantly different between severe $(66.1 \% \mathrm{men})$ and mild (47.6\%, $\mathrm{P}=0.135)$ cases. As shown in Table $\mathrm{S} 1$, the severe group had a higher percentage of chronic disease, especially hypertension and diabetes, than the mild group $(59.32 \%$ vs. $33.33 \%, \mathrm{P}=0.041)$. The most common symptoms were fever $(87.50 \%)$, dry cough $(48.75 \%)$, shortness of breath $(15.00 \%)$, myalgia $(12.50 \%)$, fatigue $(11.25 \%)$, and expectoration $(10.00 \%)$.

\section{Significant differences in immune profiles between patients with mild and severe COVID-19 on admission}

Remarkably, significant differences in blood immune cells and infection-related biomarkers were observed between the mild and severe groups (Table 1). Patients with severe conditions exhibited a higher level of neutrophils ( $90.95 \%$ vs. 64.9\%; $\mathrm{P}<0.001)$ and white blood cell counts (WBC, 9.80 vs. 4.60; $\mathrm{P}<0.001)$, and a lower percentage of lymphocytes (4.80\% vs. $23.10 \% ; \mathrm{P}<0.001)$, monocytes $(3.45 \%$ vs. $8.65 \% ; \mathrm{P}<0.001)$, and eosinophils $(0.00 \%$ vs. $0.10 \%$; $\mathrm{P}<0.001)$. Compared with patients in the mild group, those with severe cases displayed elevated levels of infectionrelated biomarkers, including high sensitivity C-reactive protein (hs-CRP, 33.94 vs. 7.62; $\mathrm{P}=0.002$ ), and erythrocyte sedimentation rate (ESR, 49.00 vs. 16.00; $\mathrm{P}<0.001)$. TNF- $\alpha$ (5.94 vs. 3.05, $\mathrm{P}=0.001$ ) and IL-10 (5.94 vs. 3.05; $\mathrm{P}=0.001$ ) levels were higher in patients with severe conditions than in those with mild cases. Although IL-2, IL-4, IL-6 also had an upward trend, the differences between the mild and severe groups were not statistically significant. Notably, patients with severe conditions exhibited slightly elevated aspartate aminotransferase (AST, 24.00 vs. 20.00, $\mathrm{P}=0.043$ ) and blood lactic acid (1.95 vs. $1.50, \mathrm{P}=0.003)$ but mildly decreased calcium (2.06 vs. 2.17; $\mathrm{P}=0.001)$ and albumin (34.55 vs. 44.10; $\mathrm{P}<0.001$ ) levels (Table $\mathrm{S} 2$ ).

To explore the role of immune cells in coronavirus disease, immune cell subsets were analyzed in 56 patients (10 mild and 46 severe cases with complete data available, Table 2). The absolute lymphocyte count per microliter was dramatically decreased in severe patients $(462.00$ vs. $1,597.50 / \mu \mathrm{L} ; \mathrm{P}<0.001)$. The three main lymphocyte subset numbers- $\mathrm{B}$ cells, T cells, and NK cells-were also generally reduced in severe patients compared to mild patients. T cells and NK cell counts were less than half of the lower reference limit while B cells were slightly above the normal range, suggesting that $\mathrm{NK}$ and $\mathrm{T}$ cells may be more affected by SARS-CoV-2 in severe patients than mild patients. Among T cells, both helper T (Th) cells (CD3+, $\mathrm{CD} 4+)$ and suppressor $\mathrm{T}(\mathrm{Ts})$ cells $(\mathrm{CD} 3+, \mathrm{CD} 8+)$ were remarkably reduced in patients with severe COVID-19 compared to those with mild cases. Finally, abnormal clinical indicators observed in severe patients reverted to the normal range during convalescence.

\section{The dynamic progression of 8 patients through admission, deteriorated, and convalescent stages}

We retrospectively analyzed all patients with COVID-19 and found that 8 patients had subsequently progressed through the stages of admission, deterioration, and convalescence. To do this, we collected clinical data of these patients as they were admitted, deteriorated, and recovered, and analyzed laboratory data available only (Figure 2). The median duration from admission to deterioration was 5 (4-6) days. As the disease progressed, a dynamic variation in lymphocyte, monocyte, basophil, and eosinophil levels was observed; first declining and then rising. However, neutrophils and hs-CRP showed the opposite trend, consistent with previous findings (Figure 2). Other laboratory data of three consecutive stages are listed in Table S3.

\section{The dynamic immune pattern changes in patients with severe COVID-19 undergoing CRRT}

CRRT contributes to the stabilization of metabolic and 
Table 1 Immune findings in patients with mild and severe COVID-19

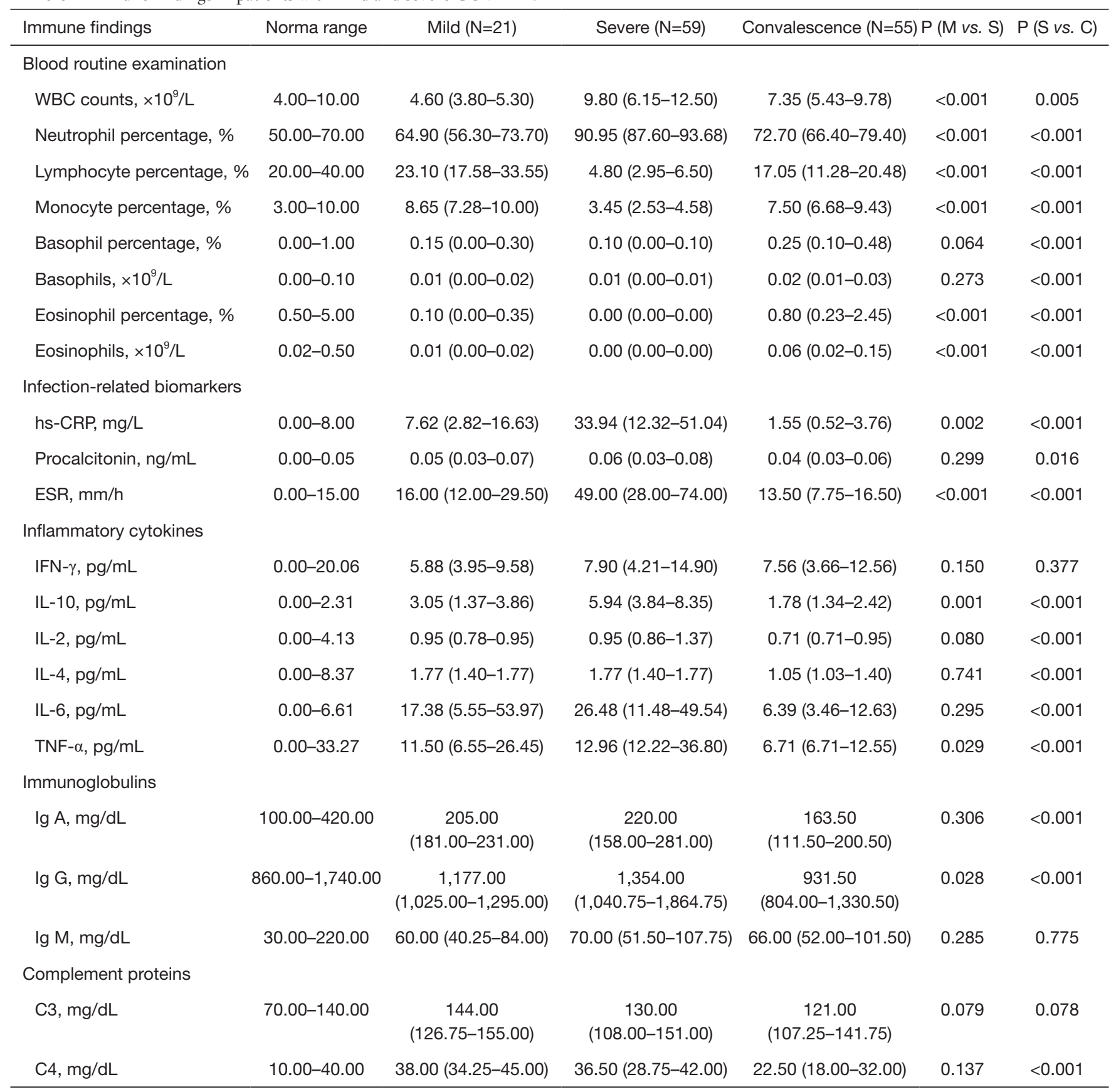

Data are presented with median (IQR). $\mathrm{N}$ is the total number of patients with available data. $\mathrm{P}$ values are obtained by $t$ test, or MannWhitney U test. IQR, interquartile range; WBC, white blood cell. hs-CRP, high sensitivity C-reactive protein. ESR, erythrocyte sedimentation rate. IFN, interferon. IL, interleukin. TNF, tumor necrosis factor. Ig, immunoglobulin. C3, complement 3. C4, complement 4.

hemodynamic status, preventing organs from further damage (13). Previously, Dastan et al. (24) reported that abnormal inflammatory cytokines in a patient with COVID-19 were relieved after administering CRRT therapy. However, research on immune homeostasis and CRRT is still limited. Among the 59 patients with severe COVID-19, 6 patients receiving CRRT were recruited and the dynamic changes in the immune pattern after receiving 
Table 2 Immune cell analysis in patients with mild and severe COVID-19

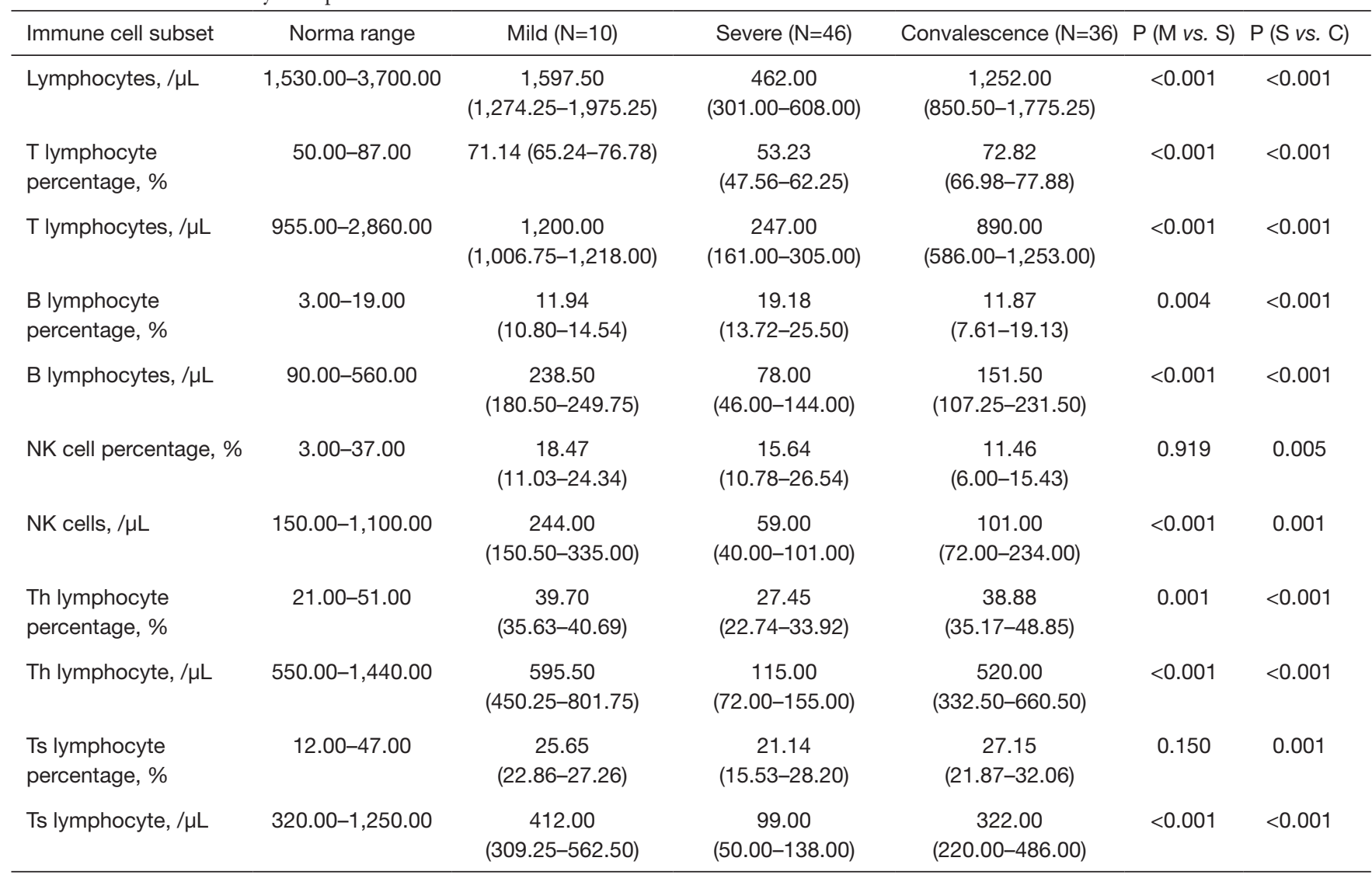

Data are presented with median (IQR). $\mathrm{N}$ is the total number of patients with available data. $\mathrm{P}$ values are obtained by $t$ test, or MannWhitney U test. T lymphocytes (CD3+CD19-). B lymphocytes (CD3-CD19+). NK, natural killer cells (CD3-CD16+ and/or CD56+). Th, helper T lymphocytes (CD3+CD4+). Ts, suppressor T lymphocytes (CD3+CD8+). IQR, interquartile range.

CRRT were examined. The details of the CRRT therapy are provided in Table $\mathrm{S} 4$.

As indicated in Figure 3, the number of immune cells, including $\mathrm{T}$ lymphocytes, B lymphocytes, helper T cells, suppressor T cells, NK cells, and monocytes slowly increased in 6 patients receiving CRRT from 0 to 3 weeks. Conversely, neutrophils, IL-6, and blood lactic acid displayed a declining trend in the 6 patients after CRRT intervention, indicating control of infection and improvement of hypoxia (Tables S5,S6).

\section{Discussion}

Infection by SARS-CoV-2 causes an immune system imbalance during the progression of pneumonia. Host immune responses, including the innate and adaptive immune responses, play a capital role in the defense against viral infections. The comparative analysis of patients with mild and severe cases found that dysregulated immune system was a common feature among patients with laboratory-confirmed COVID-19. Therefore, retrospectively analyzed peripheral blood data to examine the dynamical changes in the immune response in patients with COVID-19.

Our results were consistent with those of previous studies $(10,16)$ showing that most patients with severe illness had at least one preexisting chronic disease. These findings implied that elderly patients suffering from chronic conditions were more prone to COVID-19 probably owing to a weaker immunity.

Our analysis of laboratory data revealed that patients with severe COVID-19 presented with increased levels of neutrophils and lymphopenia compared with patients in the mild group. The opposite change in neutrophils and lymphocytes was consistent with the previous findings $(1,12,16,17)$ and indicated a serious imbalance of immune 

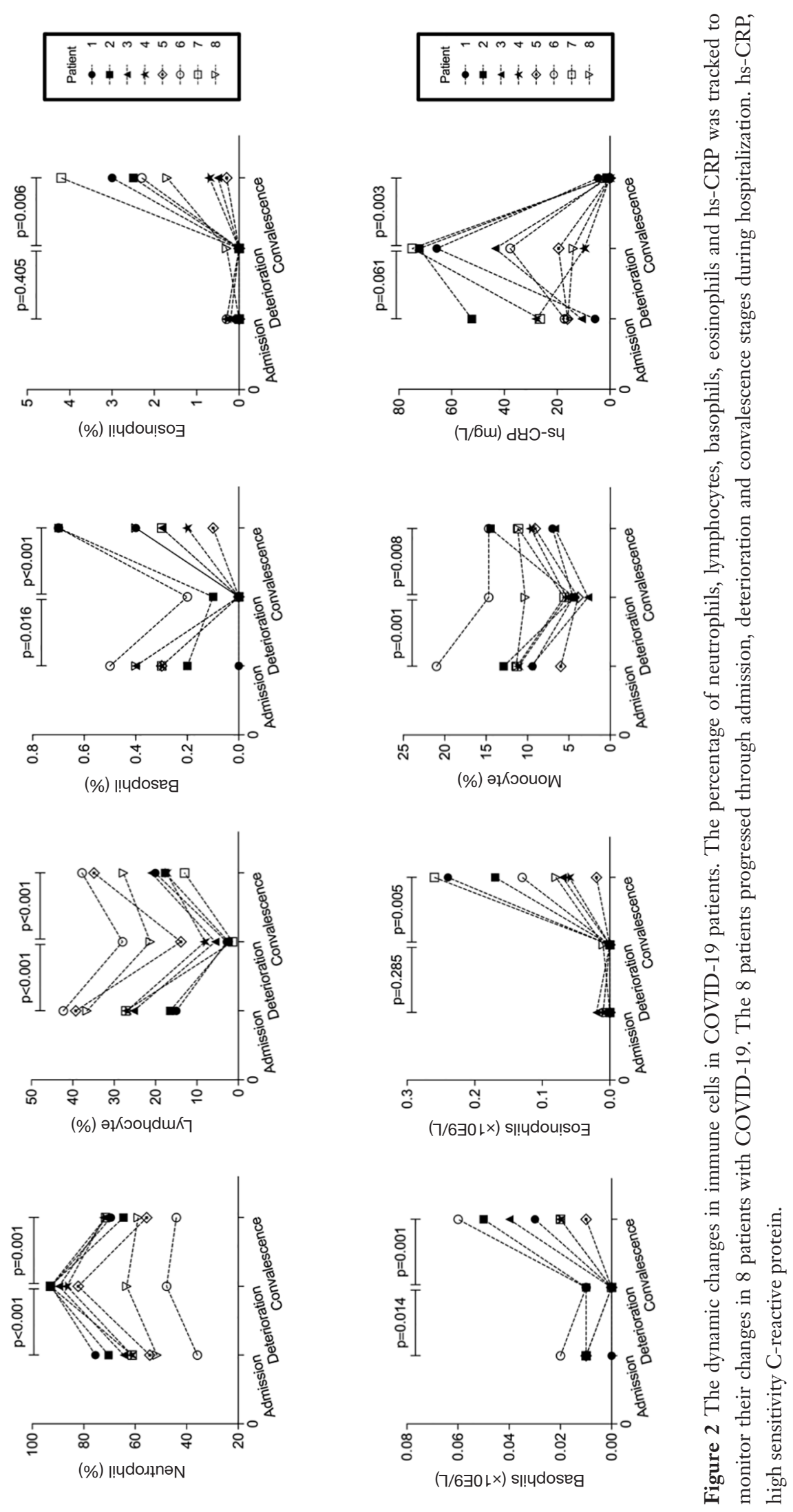


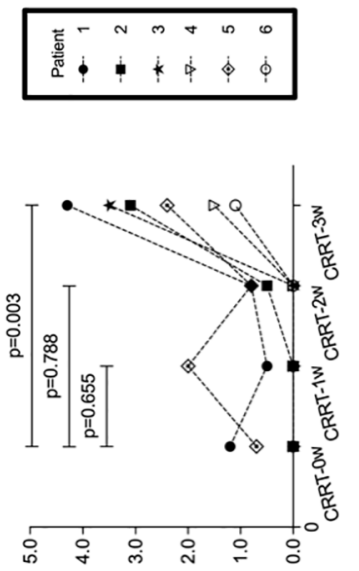

(\%) I!ydou!so
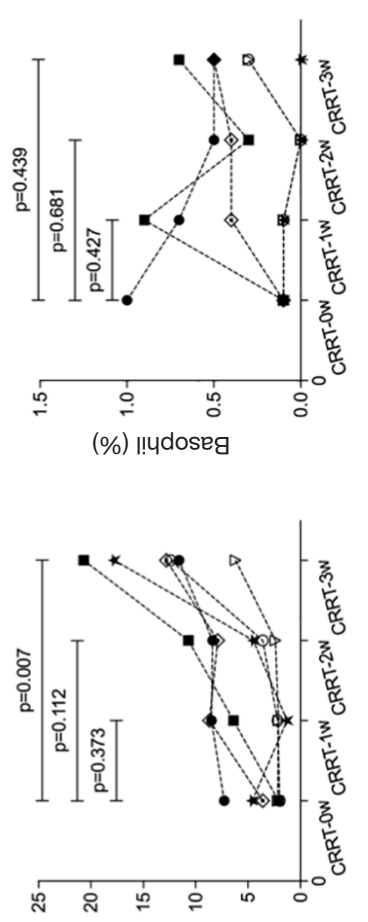

(\%) әұКэочduКา

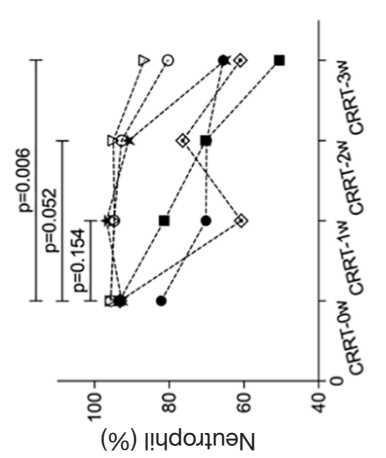

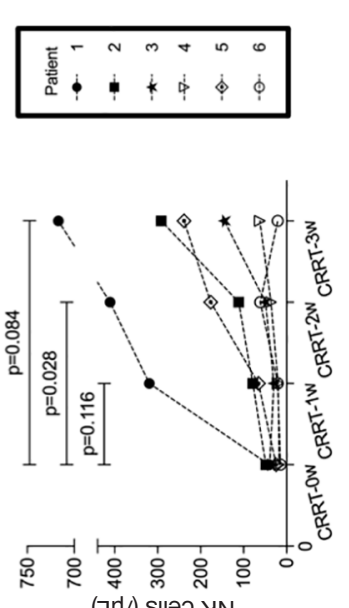

$(ך \mathrm{r} / \mathrm{s}) \mathrm{s} \| ə 0$ ㄱN

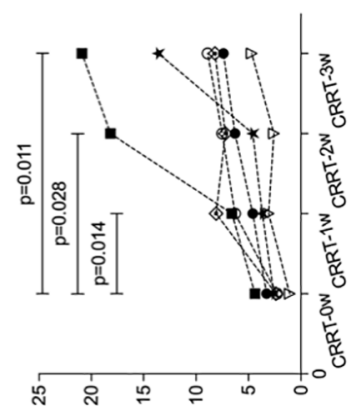

(\%) әұКэоนоW
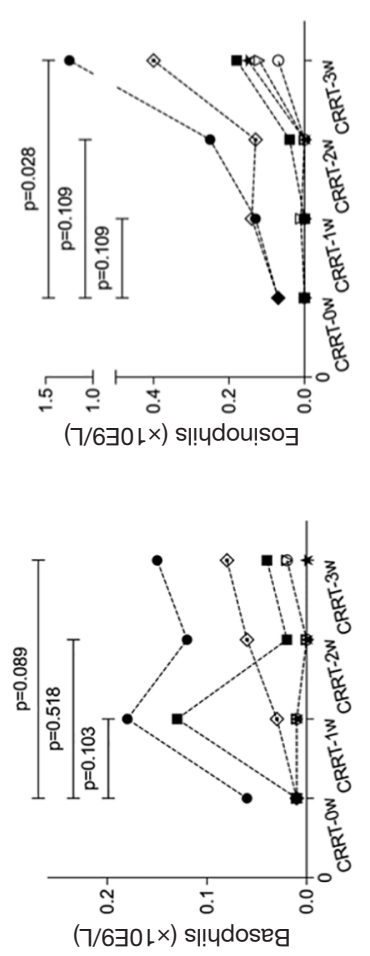

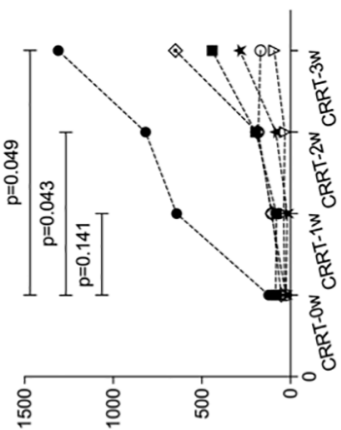

(\urcorner $\mathrm{r} / \mathrm{)}) \perp$ lossəuddns

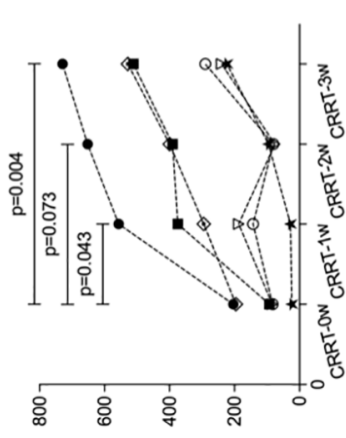

(\urcorner $\mathrm{r} /) \perp$ ıәd
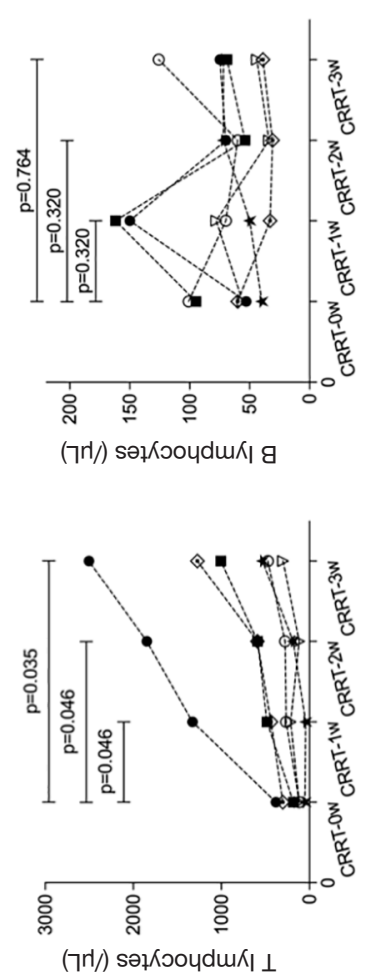

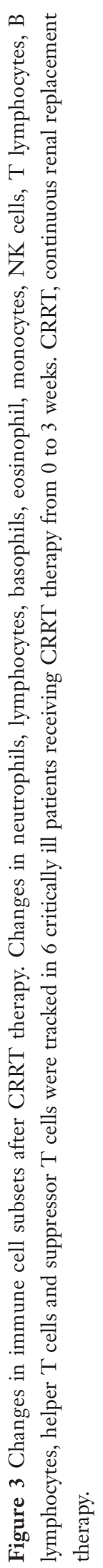

(c) Annals of Translational Medicine. All rights reserved. 
homeostasis in these patients, which was improved during convalescence. Moreover, we noticed a comprehensive reduction of all lymphocyte subsets, including CD3+CD4+ T cells, CD3+CD8+ T cells, B cells, NK cells, monocytes, basophils, and eosinophils. Two explanations for this phenomenon have been proposed. First, it is thought that blood immune cells are recruited into the infection site in the lung (15), and second, that those immune cells die due to hyperactivation of apoptosis and the P53 signaling pathway (25). The severe immune disturbance in infected patients could also be accounted for by the fact that although CD4+ or CD8+ T cells are inadequate (or scanty) in patients with COVID-19, these cells are hyperactivated, as proved by high proportions of HLA-DR and CD38 double-positive fractions (15). Monocytes also play a role in immune imbalance. Qin et al. (16) reported that regulatory $\mathrm{T}$ (Treg) cells were decreased in patients with COVID-19, and it has been suggested that Treg cells may restrain immune response by affecting monocyte-derived DC (MoDCs) (26,27). Moreover, Chen et al. (28) confirmed that IL-35-treated MoDCs exhibited potent inhibition of CD4+/CD8+ T cell immune responses. Therefore, a better understanding of the functions of immune cells after SARS$\mathrm{CoV}-2$ infection is essential.

High levels of a fatal cytokine storm have also been reported in patients with severe COVID-19 compared to patients with the mild form of the disease (16-18). In a cytokine storm, cytokines derived from innate and adaptive immune cells cause abnormalities which may result in tissue injuries and multiple organ failure. In our study, only IL10 and TNF- $\alpha$ were mainly up-regulated in the severe group. However, we also found that other proinflammatory cytokines, including IL-2, IL-4, IL-6, and Interferon- $\gamma$, were slightly elevated. In a previous study, Shi et al. (17) reported that IL-2 and IL-6 were sharply enhanced in severe patients 15-20 days after inpatient admission. Therefore, we collected the clinical data where patients were probably in early deterioration. Our analysis showed that besides cytokines, infection-related markers (hs-CRP, D-dimer, and ESR) were also elevated when patients' status deteriorated.

Notable variations in immunoglobulins have also been observed. Currently, detection of SARS-CoV-2specific $\operatorname{IgM}$ and $\operatorname{IgG}$ is used to diagnose patients with COVID-19. In our previous study, a higher IgG level was also found in patients with severe disease, consistent with previous research $(18,29)$. As Tirado et al. $(30,31)$ reported, virus-specific antibodies can enhance the entry of the virus into the host cells, and in some cases, also enhance virus replication, through interaction with $\mathrm{Fc}$ and/or complement receptors, including monocytes, macrophages, and granulocytic cells, leading to the depletion of immune cells in peripheral blood. Furthermore, the presence of $\mathrm{IgG}$ before viral clearance abrogated wound-healing responses and accelerated the recruitment of proinflammatory monocytes/macrophages in pathological tissue (32). The aberrant immunoglobulin response was attenuated during convalescence. In this study, we analyzed the dynamic modifications in immune cell populations in patients with COVID-19 who underwent the admission, deterioration, and convalescent stages and obtained identical results to those of the comparative analysis of patients with mild and severe disease.

Notably, our results showed that D-dimer levels became elevated as the patients continued to deteriorate. Some reports $(33,34)$ have indicated that D-dimer levels were significantly associated with acute kidney injury (AKI) and that D-dimer levels on admission were an independent predictor of contrast-induced acute kidney injury and longterm mortality (35). Therefore, D-dimer levels and the multiple organs that might be involved should be constantly monitored and the necessary preventive treatment measures implemented in time.

In our study, critically ill patients additionally received CRRT, which slowly improved their overall immune state. Pohl et al. (36) were the first to report that CRRT therapy could reduce the high circulating macrophage migration inhibitory factor, which amplified the immune response, to reduce mortality due to severe sepsis. Subsequently, several studies showed that CRRT modulated the immune imbalance and improved prognosis in most critically ill patients with septic shock or severe pancreatitis by increasing cellular immunity and restoring monocyte functions (37-41). Moreover, CRRT was also suggested for inclusion in the early stage of bundle therapy for severe pneumonia as an effective way to clear inflammatory mediators, improve immune function, reduce complications and delay the rapid progression of severe pneumonia (42). Currently, extracorporeal membrane oxygenation (ECMO) is used for treating critically ill patients with COVID-19 (43). However, Hu et al. (44) showed that ECMO promoted the release of inflammatory cytokines, induced immune disorders, and impaired renal function, and ECMO combined with CRRT treatment could maintain immune balance and alleviate renal injuries in vivo studies. Further research to explore the effect of CRRT on the immune 


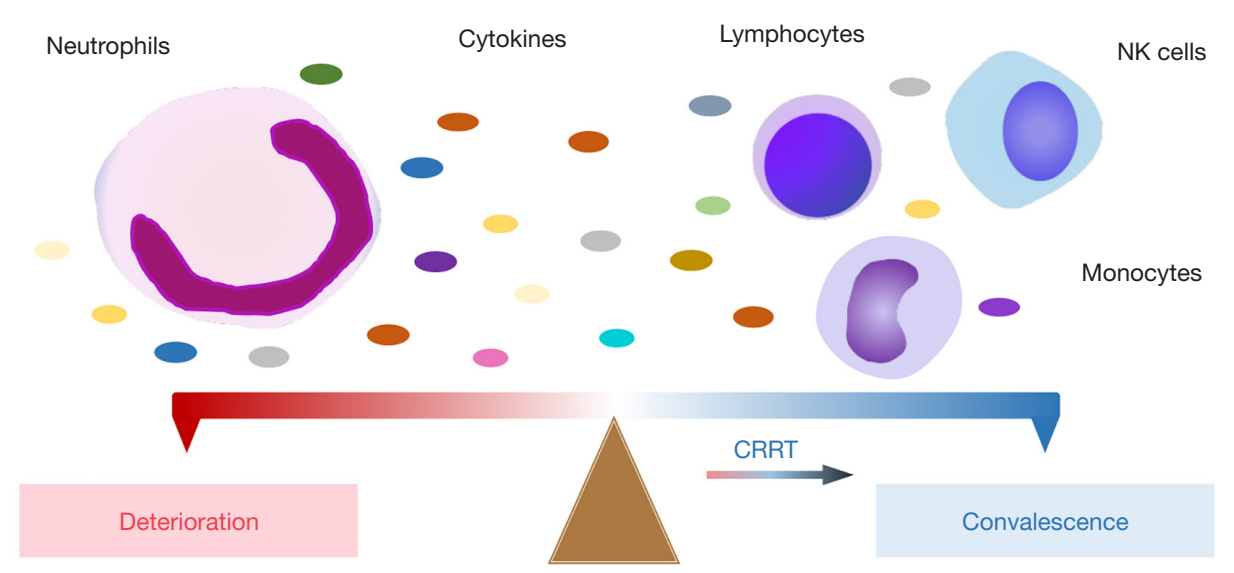

Figure 4 A schematic of the proposed mechanism of disease severity of COVID-19. Patients' conditions deteriorated accompanying an increase in neutrophils and a corresponding decrease in lymphocytes/monocytes/NK cells. Otherwise, patients gradually improved.

system is needed.

We acknowledge some limitations in our retrospective study. Firstly, this study was a single-center, small-sample study of patients with COVID-19; specifically, patients who progressed through admission, deterioration, and convalescence, and received the CRRT therapy. Secondly, repeated infection or secondary infection might affect the findings. Thirdly, the CRRT group lacked a comparable control group. Nevertheless, our findings highlighted that patients with severe COVID-19 were associated with lymphopenia, neutrophilia, abnormalities of cytokines, and immunoglobulin and that CRRT therapy contributed to the restoration of immune homeostasis (Figure 4). The immunopathological mechanism of SARS-CoV-2 in innate and adaptive immune cells warrants further exploration.

\section{Conclusions}

Overall, the surveillance of immune cells can be used to monitor COVID-19 disease progression and have direct implications for symptomatic treatment and patient care. Besides, CRRT intervention alleviated the aberrant immune response in critically ill patients, which could be considered as a potential therapeutic strategy. Finally, we believe that our study makes a significant contribution to the literature, chiefly in the context of the rapidly evolving COVID-19 pandemic, and provides a foundational analysis of clinical data to build on by other researchers in the field of immunology.

\section{Acknowledgments}

We frankly thank all patients, researchers, and medical workers for their significant contributions to fighting against the COVID-19.

Funding: None.

\section{Footnote}

Reporting Checklist: The authors have completed the STROBE reporting checklist. Available at https://dx.doi. org/10.21037/atm-21-812

Data Sharing Statement: The data relevant to this study are available from the corresponding author on reasonable request. Available at https://dx.doi.org/10.21037/atm-21812

Conflicts of Interest: All authors have completed the ICMJE uniform disclosure form (available at https://dx.doi. org/10.21037/atm-21-812). The authors have no conflicts of interest to declare.

Ethics Statement: The authors are accountable for all aspects of the work in ensuring that questions related to the accuracy or integrity of any part of the work are appropriately investigated and resolved. The study was conducted following the Declaration of Helsinki (as revised in 2013). The study was approved by the Clinical Research Ethics Committee of the First Affiliated Hospital, College 
of Medicine, Zhejiang University (No. 2020IIT195), and individual consents for this retrospective analysis were waived.

Open Access Statement: This is an Open Access article distributed in accordance with the Creative Commons Attribution-NonCommercial-NoDerivs 4.0 International License (CC BY-NC-ND 4.0), which permits the noncommercial replication and distribution of the article with the strict proviso that no changes or edits are made and the original work is properly cited (including links to both the formal publication through the relevant DOI and the license). See: https://creativecommons.org/licenses/by-nc-nd/4.0/.

\section{References}

1. Wu F, Zhao S, Yu B, et al. A new coronavirus associated with human respiratory disease in China. Nature 2020;579:265-9.

2. Tang Y, Wang S. Mathematic modeling of COVID-19 in the United States. Emerg Microbes Infect 2020;9:827-9.

3. Asselah T, Durantel D, Pasmant E, et al. COVID-19: Discovery, diagnostics and drug development. J Hepatol 2021;74:168-84.

4. van Doremalen N, Bushmaker T, Morris DH, et al. Aerosol and Surface Stability of SARS-CoV-2 as Compared with SARS-CoV-1. N Engl J Med 2020;382:1564-7.

5. Hu B, Guo H, Zhou P, et al. Characteristics of SARS-CoV-2 and COVID-19. Nat Rev Microbiol 2021;19:141-54.

6. Stadnytskyi V, Bax CE, Bax A, et al. The airborne lifetime of small speech droplets and their potential importance in SARS-CoV-2 transmission. Proc Natl Acad Sci U S A 2020;117:11875-7.

7. Meselson M. Droplets and Aerosols in the Transmission of SARS-CoV-2. N Engl J Med 2020;382:2063.

8. Moghadas SM, Fitzpatrick MC, Sah P, et al. The implications of silent transmission for the control of COVID-19 outbreaks. Proc Natl Acad Sci U S A 2020;117:17513-5.

9. Brodin P. Immune determinants of COVID-19 disease presentation and severity. Nat Med 2021;27:28-33.

10. Huang C, Wang Y, Li X, et al. Clinical features of patients infected with 2019 novel coronavirus in Wuhan, China. Lancet 2020;395:497-506.

11. Chen N, Zhou M, Dong X, et al. Epidemiological and clinical characteristics of 99 cases of 2019 novel coronavirus pneumonia in Wuhan, China: a descriptive study. Lancet 2020;395:507-13.

12. Wang $\mathrm{D}, \mathrm{Hu} \mathrm{B}, \mathrm{Hu} \mathrm{C}$, et al. Clinical Characteristics of 138 Hospitalized Patients With 2019 Novel CoronavirusInfected Pneumonia in Wuhan, China. JAMA 2020;323:1061-9.

13. Fu D, Yang B, Xu J, et al. COVID-19 Infection in a Patient with End-Stage Kidney Disease. Nephron 2020;144:245-7.

14. Huang C, Huang L, Wang Y, et al. 6-month consequences of COVID-19 in patients discharged from hospital: a cohort study. Lancet 2021;397:220-32.

15. Xu Z, Shi L, Wang Y, et al. Pathological findings of COVID-19 associated with acute respiratory distress syndrome. Lancet Respir Med 2020;8:420-2.

16. Qin C, Zhou L, Hu Z, et al. Dysregulation of immune response in patients with COVID-19 in Wuhan, China. Clin Infect Dis 2020;71:762-8.

17. Shi $Y$, Tan $M$, Chen $X$, et al. Immunopathological characteristics of coronavirus disease 2019 cases in Guangzhou, China. Immunology 2020;160:261-8.

18. Zhang B, Zhou X, Zhu C, et al. Immune phenotyping based on neutrophil-to-lymphocyte ratio and IgG predicts disease severity and outcome for patients with COVID-19. Front Mol Biosci 2020;7:157.

19. Zheng M, Gao Y, Wang G, et al. Functional exhaustion of antiviral lymphocytes in COVID-19 patients. Cell Mol Immunol 2020;17:533-5.

20. Liao M, Liu Y, Yuan J, et al. Single-cell landscape of bronchoalveolar immune cells in patients with COVID-19. Nat Med 2020;26:842-4.

21. Merad M, Martin JC. Pathological inflammation in patients with COVID-19: a key role for monocytes and macrophages. Nat Rev Immunol 2020;20:355-62.

22. Dai L, Gao GF. Viral targets for vaccines against COVID-19. Nat Rev Immunol 2021;21:73-82.

23. Chung JY, Thone MN, Kwon YJ. COVID-19 vaccines: The status and perspectives in delivery points of view. Adv Drug Deliv Rev 2021;170:1-25.

24. Dastan F, Saffaei A, Mortazavi SM, et al. Continues renal replacement therapy (CRRT) with disposable hemoperfusion cartridge: A promising option for severe COVID-19. J Glob Antimicrob Resist 2020;21:340-1.

25. Xiong Y, Liu Y, Cao L, et al. Transcriptomic characteristics of bronchoalveolar lavage fluid and peripheral blood mononuclear cells in COVID-19 patients. Emerg Microbes Infect 2020;9:761-70.

26. Misra N, Bayry J, Lacroix-Desmazes S, et al. Cutting edge: human CD4+CD25+ T cells restrain the maturation and 
antigen-presenting function of dendritic cells. J Immunol 2004;172:4676-80.

27. Oderup C, Cederbom L, Makowska A, et al. Cytotoxic T lymphocyte antigen-4-dependent down-modulation of costimulatory molecules on dendritic cells in CD4+ CD25+ regulatory T-cell-mediated suppression. Immunology 2006;118:240-9.

28. Chen X, Hao S, Zhao Z, et al. Interleukin 35: Inhibitory regulator in monocyte-derived dendritic cell maturation and activation. Cytokine 2018;108:43-52.

29. Zhao J, Yuan Q, Wang H, et al. Antibody Responses to SARS-CoV-2 in Patients With Novel Coronavirus Disease 2019. Clin Infect Dis 2020;71:2027-34.

30. Tirado SM, Yoon KJ. Antibody-dependent enhancement of virus infection and disease. Viral Immunol 2003;16:69-86.

31. Cao X. COVID-19: immunopathology and its implications for therapy. Nat Rev Immunol 2020;20:269-70.

32. Liu L, Wei Q, Lin Q, et al. Anti-spike IgG causes severe acute lung injury by skewing macrophage responses during acute SARS-CoV infection. JCI Insight

33. Han H, Li J, Chen D, et al. A Clinical Risk Scoring System of Acute Respiratory Distress Syndrome-Induced Acute Kidney Injury. Med Sci Monit 2019;25:5606-12.

34. Xu Z, Cheng B, Fu S, et al. Coagulative biomarkers on admission to the ICU predict acute kidney injury and mortality in patients with septic shock caused by intraabdominal infection. Infect Drug Resist 2019;12:2755-64.

35. Lin KY, Chen HC, Jiang H, et al. Predictive value of admission D-dimer for contrast-induced acute kidney injury and poor outcomes after primary percutaneous coronary intervention. BMC Nephrol 2020;21:90.

36. Pohl J, Papathanasiou M, Heisler M, et al. Renal replacement therapy neutralizes elevated MIF levels in

Cite this article as: Ren P, Zhu C, He Y, Jiang H, Chen J. Analysis of the dynamic relationship between immune profiles and the clinical features of patients with COVID-19. Ann Transl Med 2021;9(14):1118. doi: 10.21037/atm-21-812 septic shock. J Intensive Care 2016;4:39.

37. Schwindenhammer V, Girardot T, Chaulier K, et al. oXiris@ Use in Septic Shock: Experience of Two French Centres. Blood Purif 2019;47 Suppl 3:1-7.

38. Zhou LX, Tan JJ, Li YN, et al. Immune and inflammation confusion in severe sepsis and effects of biimmunomodulation therapy: a prospective, randomized, controlled clinical trial. Zhonghua Yi Xue Za Zhi 2009;89:1028-33.

39. Ronco C, Bellomo R, Ricci Z. Continuous renal replacement therapy in critically ill patients. Nephrol Dial Transplant 2001;16 Suppl 5:67-72.

40. Li YN, Zhou LX, Qiang XH, et al. Effect of continuous blood purification and thymosin alpha1 on the cellular immunity in patients with severe sepsis: a prospective, randomized, controlled clinical trial. Zhongguo Wei Zhong Bing Ji Jiu Yi Xue 2009;21:139-42.

41. Yu C, Liu ZH, Chen ZH, et al. Improvement of monocyte function and immune homeostasis by high volume continuous venovenous hemofiltration in patients with severe acute pancreatitis. Int J Artif Organs 2008;31:882-90.

42. Xu J, Zhao J, Jia X, et al. Application of early continuous renal replacement therapy in the bundle treatment of severe pneumonia. Zhonghua Wei Zhong Bing Ji Jiu Yi Xue 2018;30:246-50.

43. Li X, Guo Z, Li B, et al. Extracorporeal Membrane Oxygenation for Coronavirus Disease 2019 in Shanghai, China. ASAIO J 2020;66:475-81.

44. Yimin H, Wenkui Y, Jialiang S, et al. Effects of continuous renal replacement therapy on renal inflammatory cytokines during extracorporeal membrane oxygenation in a porcine model. J Cardiothorac Surg 2013;8:113. 


\section{Supplementary}

Table S1 Basic characteristics in patients with mild and severe COVID-19

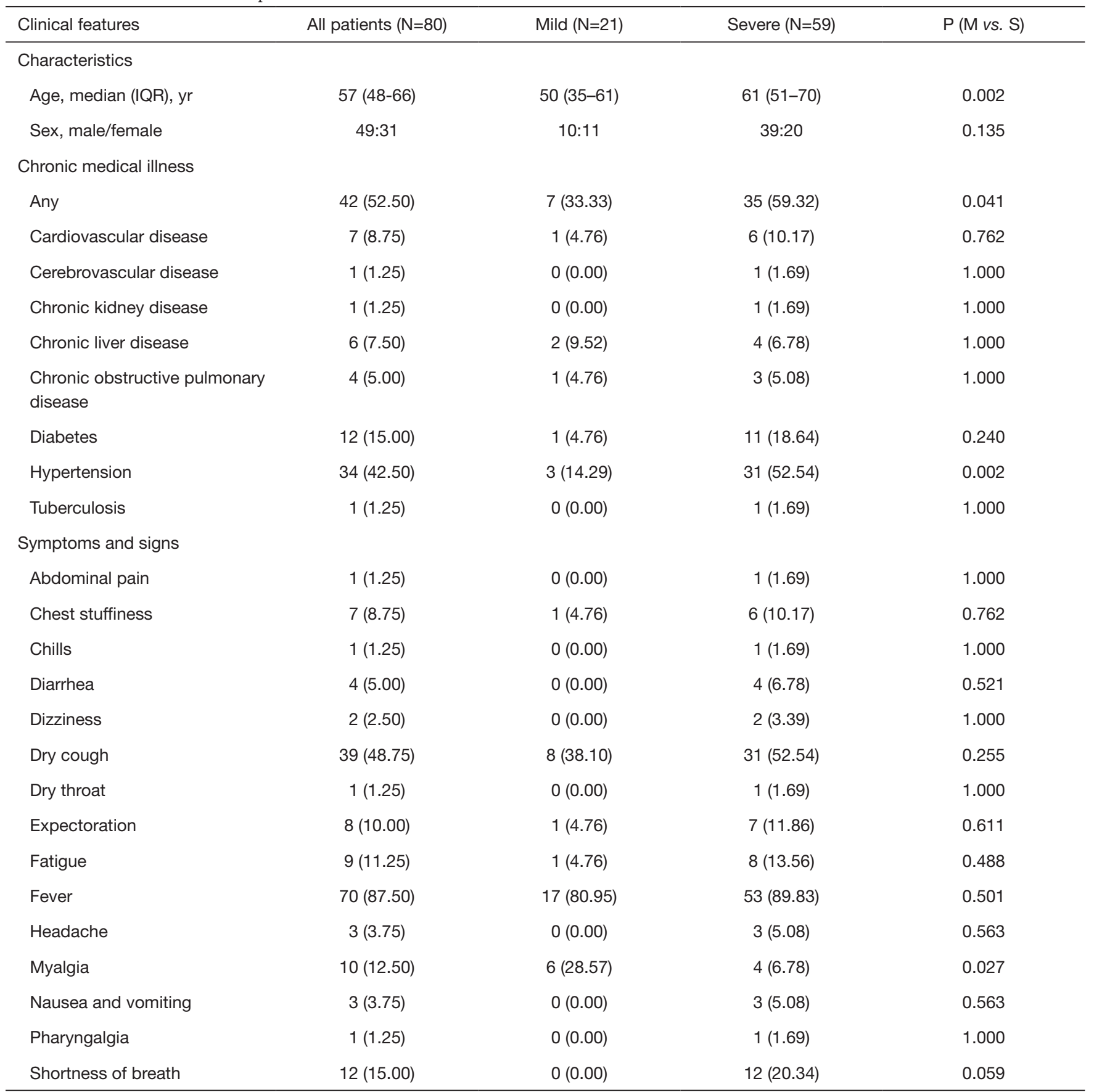

Data are presented with median (IQR), Ratio, $\mathrm{n}(\%)$, in which $\mathrm{N}$ is the total number of patients with available data. IQR, interquartile range.

$P$ values comparing mild and severe group are obtained by $\chi^{2}$ test, Fisher' exact test, or Mann-Whitney $U$ test. yr, year (s). 
Table S2 Biochemical findings in patients with mild and severe COVID-19

\begin{tabular}{|c|c|c|c|c|c|c|}
\hline Biochemical Indicators & Norma Range & Mild $(\mathrm{N}=21)$ & Severe $(N=59)$ & Convalescence $(\mathrm{N}=55)$ & $\mathrm{P}(\mathrm{M}$ vs. S) & $\mathrm{P}$ (S vs. C) \\
\hline Blood Lactic Acid, mmol/L & $0.50-1.60$ & $1.50(1.20-1.70)$ & $1.95(1.60-2.53)$ & $1.80(1.20-2.40)$ & 0.003 & 0.070 \\
\hline D-dimer, $\mu \mathrm{g} / \mathrm{L}$ FEU & $0.00-700.00$ & $262.50(175.75-596.00)$ & $813.00(363.00-1549.75)$ & $568.50(346.00-1222.25)$ & $<0.001$ & 0.213 \\
\hline Urea, mmol/L & $3.60-9.50$ & $4.29(3.35-4.76)$ & $6.12(4.61-8.40)$ & $5.57(4.75-7.88)$ & $<0.001$ & 0.635 \\
\hline Uric acid, $\mu \mathrm{mol} / \mathrm{L}$ & $208.00-428.00$ & $237.50(195.50-334.50)$ & 220.00 (170.00-282.50) & $215.00(166.00-278.25)$ & 0.412 & 0.384 \\
\hline Creatinine, $\mu \mathrm{mol} / \mathrm{L}$ & $57.00-111.00$ & $66.00(55.00-89.00)$ & $72.00(64.00-88.00)$ & $70.00(56.25-77.75)$ & 0.248 & 0.043 \\
\hline eGFR (EPI-Cr) & & $94.41(77.83-102.23)$ & $92.01(72.32-105.67)$ & $98.16(91.63-105.39)$ & 0.724 & 0.055 \\
\hline Globulin, g/L & $20.00-40.00$ & $26.25(23.35-28.45)$ & $28.70(25.80-33.60)$ & $24.90(21.45-29.80)$ & 0.010 & $<0.001$ \\
\hline Albumin, g/L & $40.00-55.00$ & $44.10(40.40-46.60)$ & $34.55(31.80-39.10)$ & $38.10(33.60-40.85)$ & $<0.001$ & 0.011 \\
\hline$A L T, U / L$ & $9.00-50.00$ & $20.00(13.00-26.00)$ & $21.50(14.00-37.25)$ & $40.50(26.25-61.00)$ & 0.342 & $<0.001$ \\
\hline AST, U/L & $15.00-40.00$ & $20.00(18.00-22.00)$ & $24.00(17.00-36.00)$ & $21.00(15.00-25.50)$ & 0.043 & 0.003 \\
\hline Total Bilirubin, $\mu \mathrm{mol} / \mathrm{L}$ & $0.00-26.00$ & $10.45(5.58-12.28)$ & $10.75(7.90-17.70)$ & $9.80(6.60-12.40)$ & 0.157 & 0.062 \\
\hline Hemoglobin, $g / L$ & $131.00-172.00$ & $135.00(122.50-147.75)$ & $133.00(121.00-146.75)$ & $121.00(104.00-132.50)$ & 0.376 & $<0.001$ \\
\hline Hematocrit, \% & $38.00-50.80$ & $40.70(36.33-43.10)$ & $38.60(34.55-43.10)$ & $36.55(31.33-40.85)$ & 0.296 & 0.009 \\
\hline Blood platelet, x10E9/L & $83.00-303.00$ & $187.00(141.50-271.00)$ & $189.50(156.00-232.75)$ & $171.50(118.25-224.75)$ & 0.668 & 0.152 \\
\hline Natrium, mmol/L & $137.00-147.00$ & $140.00(138.00-141.00)$ & $138.00(136.00-140.00)$ & $140.00(139.00-142.00)$ & 0.015 & 0.001 \\
\hline Potassium, $\mathrm{mmol} / \mathrm{L}$ & $3.50-5.30$ & $3.69(3.53-4.15)$ & $3.90(3.59-4.07)$ & $3.98(3.69-4.20)$ & 0.459 & 0.197 \\
\hline Total Calcium, mmol/L & $2.11-2.52$ & $2.17(2.10-2.28)$ & $2.06(1.99-2.17)$ & $2.16(2.06-2.27)$ & 0.001 & $<0.001$ \\
\hline
\end{tabular}

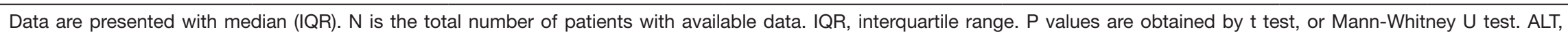
alanine aminotransferase. AST, aspartate aminotransferase.

Table S3 Biochemical findings in dynamic patients with COVID-19

\begin{tabular}{|c|c|c|c|c|c|c|}
\hline Biochemical Indicators & Norma Range & Hospitalization ( $\mathrm{N}=8$ ) & Deterioration $(\mathrm{N}=8)$ & Convalescence $(\mathrm{N}=8)$ & $\mathrm{P}(\mathrm{H}$ vs. D) & $P(D$ vs. $C)$ \\
\hline Urea, mmol/L & $3.60-9.50$ & $4.03(3.03-5.53)$ & $7.35(4.41-8.35)$ & $4.78(4.00-6.23)$ & 0.029 & 0.094 \\
\hline Uric acid, $\mu \mathrm{mol} / \mathrm{L}$ & $208.00-428.00$ & $265.50(235.25-348.00)$ & $224.00(215.75-235.50)$ & $254.00(211.25-328.00)$ & 0.104 & 0.091 \\
\hline Creatinine, $\mu \mathrm{mol} / \mathrm{L}$ & $57.00-111.00$ & 82.50 (76.00-92.50) & $71.50(62.50-76.75)$ & $67.50(58.50-69.75)$ & 0.007 & 0.178 \\
\hline eGFR (EPI-Cr) & & $95.22(87.03-102.95)$ & 105.60 (98.71-121.74) & 114.19 (99.42-120.92) & 0.033 & 0.574 \\
\hline Globulin, g/L & $20.00-40.00$ & $27.30(26.73-31.28)$ & 38.35 (26.33-41.80) & $25.50(21.45-33.25)$ & 0.093 & 0.013 \\
\hline Albumin, g/L & $40.00-55.00$ & $42.05(38.60-44.98)$ & $35.30(31.00-36.95)$ & $39.75(37.75-41.75)$ & 0.001 & 0.006 \\
\hline ALT, U/L & $9.00-50.00$ & $18.50(12.00-27.75)$ & $15.50(11.00-18.25)$ & $48.50(21.50-71.75)$ & 0.325 & 0.161 \\
\hline AST, U/L & $15.00-40.00$ & $20.50(16.50-27.75)$ & $16.50(13.75-19.00)$ & $19.00(13.25-34.00)$ & 0.310 & 0.398 \\
\hline Total Bilirubin, umol/L & $0.00-26.00$ & $10.90(9.70-14.28)$ & $12.75(9.33-22.90)$ & 10.70 (8.75-13.28) & 0.272 & 0.098 \\
\hline Hemoglobin, g/L & $131.00-172.00$ & $150.50(137.50-153.75)$ & $133.00(120.00-136.00)$ & $128.50(118.50-135.50)$ & 0.003 & 0.575 \\
\hline Hematocrit, \% & $38.00-50.80$ & $43.30(41.15-44.93)$ & $38.80(36.38-40.78)$ & 38.15 (36.25-40.03) & 0.004 & 0.662 \\
\hline Blood platelet, x10E9/L & $83.00-303.00$ & $151.50(131.75-184.00)$ & $243.50(201.75-271.50)$ & $223.50(173.75-284.75)$ & $<0.001$ & 0.570 \\
\hline Natrium, mmol/L & $137.00-147.00$ & $139.50(138.00-140.75)$ & $136.00(136.00-138.75)$ & $140.00(135.50-141.75)$ & 0.120 & 0.065 \\
\hline Potassium, mmol/L & $3.50-5.30$ & $3.74(3.49-3.90)$ & $4.26(3.75-4.75)$ & $3.94(3.77-4.34)$ & 0.070 & 0.396 \\
\hline Total Calcium, mmol/L & $2.11-2.52$ & $2.15(2.06-2.26)$ & $2.09(1.92-2.16)$ & $2.20(2.10-2.28)$ & 0.063 & 0.026 \\
\hline
\end{tabular}

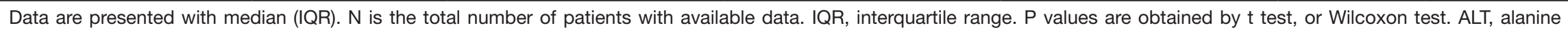
aminotransferase. AST, aspartate aminotransferase. 
Table S4 The detailed information about CRRT therapy

\begin{tabular}{|c|c|c|c|c|c|c|c|c|c|c|c|c|}
\hline Patients & Age & Sex & Life support & Comorbidities & Model & Duration (h) & Vascular Access Site & Blood Flow (ml/min) & Anticoagulation & Replacement fluid (m//h) & Dialysate $(\mathrm{m} / \mathrm{h})$ & Ultrafiltration rate $(\mathrm{m} / \mathrm{h})$ \\
\hline Patient 1 & 75 & Male & Mechanical Ventilation+ECMO & Hypertension, diabetes, tuberculosis & $\mathrm{CVVH}$ & 24 & Right femoral vein & 250 & Heparin-free/citrate & 3000 & 0 & 200 \\
\hline Patient 2 & 91 & Male & Mechanical Ventilation & Hypertension, cardiovascular disease & $\mathrm{CVVH}$ & 24 & Right femoral vein & 230 & Low molecular weight heparin & 2000 & 0 & $150-200$ \\
\hline Patient 3 & 62 & Male & High-frequency Ventilation & Hypertension, dabetes & $\mathrm{CVVH}$ & 8-12 & Right femoral vein & 220 & Low molecular weight heparin & 3000 & 0 & $150-200$ \\
\hline Patient 4 & 82 & Female & Mechanical Ventilation+ECMO & Hypertension, cardiovascular disease & $\mathrm{CVVH}$ & 24 & Right femoral vein & 230 & Citrate & 3000 & 0 & $150-200$ \\
\hline Patient 5 & 91 & Male & Mechanical Ventilation+ECMO & Hypertension & CVVHD & 24 & Right femoral vein & 160 & Citrate & 1000 & 1000 & 150 \\
\hline Patient 6 & 73 & Male & Mechanical Ventilation+ECMO & Hypertension & CVVHDF & $12-24$ & Left femoral vein & 150 & Heparin-free/citrate & 2000 & 0 & 150 \\
\hline
\end{tabular}

$\mathrm{CVVH}$, continuous veno-venous hemofiltration. CVVH, continuous veno-venous hemodialysis. CVVHDF, continuous veno-venous hemodiafiltration.

Table S5 Immune findings in patients with COVID-19 who received CRRT therapy

\begin{tabular}{|c|c|c|c|c|c|c|c|c|}
\hline Immune Findings & Norma Range & CRRT_0w (N=6) & CRRT_1w (N=6) & CRRT_2w ( $(\mathrm{N}=6)$ & CRRT_3w (N=6) & $P(0$ vs. $1 w)$ & $P(0$ vs. $2 w)$ & $P(0$ vs. $3 w)$ \\
\hline \multicolumn{9}{|c|}{ Infection-related Biomarkers } \\
\hline hs-CRP, mg/L & $0.00-8.00$ & $100.88(51.59-155.74)$ & $83.42(42.81-183.37)$ & $78.51(26.99-135.28)$ & $70.82(39.16-166.54)$ & 0.940 & 0.151 & 0.529 \\
\hline Procalcitonin, ng/mL & $0.00-0.05$ & $0.70(0.35-4.45)$ & $0.47(0.22-1.02)$ & $0.39(0.20-1.75)$ & $1.18(0.48-1.48)$ & 0.249 & 0.500 & 0.917 \\
\hline \multicolumn{9}{|l|}{ Inflammatory Cytokines } \\
\hline $\mathrm{IFN}-\gamma, \mathrm{pg} / \mathrm{mL}$ & $0.00-20.06$ & $11.72(2.41-29.36)$ & $10.36(7.10-20.96)$ & $6.77(3.52-15.76)$ & $9.48(6.84-33.18)$ & 0.549 & 0.394 & 0.811 \\
\hline $\mathrm{IL}-10, \mathrm{pg} / \mathrm{ml}$ & $0.00-2.31$ & $8.21(7.12-11.05)$ & $8.69(7.12-14.07)$ & $5.49(1.79-7.60)$ & $6.59(4.08-12.27)$ & 0.753 & 0.052 & 0.463 \\
\hline $\mathrm{IL}-2, \mathrm{pg} / \mathrm{ml}$ & $0.00-4.13$ & $0.83(0.71-1.08)$ & $1.15(0.71-1.95)$ & $1.05(0.71-1.67)$ & $1.41(0.65-1.68)$ & 0.685 & 0.598 & 0.194 \\
\hline $\mathrm{IL}-4, \mathrm{pg} / \mathrm{ml}$ & $0.00-8.37$ & $1.22(1.03-1.46)$ & $1.45(1.03-3.79)$ & $1.44(1.03-8.74)$ & $0.68(0.33-1.05)$ & 0.225 & 0.343 & 0.026 \\
\hline TNF- $\alpha, \mathrm{pg} / \mathrm{ml}$ & $0.00-33.27$ & $9.44(6.71-48.58)$ & $56.38(1.34-96.63)$ & $41.30(11.09-107.78)$ & $13.95(1.45-36.21)$ & 0.063 & 0.173 & 0.829 \\
\hline \multicolumn{9}{|l|}{ Immunoglobulins } \\
\hline $\lg \mathrm{A}, \mathrm{mg} / \mathrm{dL}$ & $100.00-420.00$ & $152.50(115.75-206.25)$ & $202.50(158.25-286.50)$ & $234.00(172.25-378.75)$ & $255.50(199.25-281.75)$ & 0.083 & 0.047 & 0.000 \\
\hline $\lg \mathrm{G}, \mathrm{mg} / \mathrm{dL}$ & $860.00-1740.00$ & $1883.50(1400.50-2536.50)$ & $1837.00(1439.75-2305.75)$ & $2481.00(1746.00-3246.50)$ & 2247.00 (1289.00-2909.25) & 0.989 & 0.134 & 0.531 \\
\hline $\operatorname{lg~M,~mg/dL~}$ & $30.00-220.00$ & $35.50(29.75-60.75)$ & $61.00(42.50-76.00)$ & $64.50(52.75-85.50)$ & $63.50(25.25-74.75)$ & 0.025 & 0.023 & 0.223 \\
\hline \multicolumn{9}{|l|}{ Complement Proteins } \\
\hline $\mathrm{C} 3, \mathrm{mg} / \mathrm{dL}$ & $70.00-140.00$ & $90.00(58.50-101.75)$ & $107.50(86.50-119.50)$ & $110.00(90.25-132.75)$ & $96.00(77.50-108.00)$ & 0.154 & 0.056 & 0.540 \\
\hline $\mathrm{C} 4, \mathrm{mg} / \mathrm{dL}$ & $10.00-40.00$ & $18.00(13.75-25.50)$ & $17.00(12.75-24.25)$ & $16.50(14.00-25.25)$ & $13.50(11.25-24.50)$ & 0.438 & 0.476 & 0.262 \\
\hline \multicolumn{9}{|c|}{ Data are presented with median (IQR). $N$ is the total number of patients with available data. IQR, interquartile range. } \\
\hline
\end{tabular}


Table S6 Biochemical findings in patients with COVID-19 who received CRRT therapy

\begin{tabular}{|c|c|c|c|c|c|c|c|c|}
\hline Biochemical Indicators & Norma Range & CRRT_Ow (N=6) & CRRT_1w (N=6) & CRRT_2w (N=6) & CRRT_3w (N=6) & $\mathrm{P}(0$ vs. $1 \mathrm{w})$ & $\mathrm{P}(0$ vs. $2 \mathrm{w})$ & $\mathrm{P}(0$ vs. $3 w)$ \\
\hline Blood Lactic Acid, mmol/L & $0.50-1.60$ & $3.30(2.85-4.25)$ & $2.15(1.83-2.63)$ & $1.60(1.48-2.33)$ & $1.50(1.00-1.95)$ & 0.006 & 0.004 & 0.001 \\
\hline D-dimer, ug/L FEU & $0.00-700.00$ & $7656.50(2077.00-18670.50)$ & $10680.00(3124.00-15579.25)$ & $8329.00(2847.50-16773.75)$ & $5481.50(3830.75-17970.00)$ & 0.345 & 0.978 & 0.778 \\
\hline Urea, mmol/L & $3.60-9.50$ & $18.73(10.33-31.30)$ & $6.47(4.33-19.33)$ & $9.37(6.44-16.85)$ & $8.96(5.50-13.17)$ & 0.006 & 0.015 & 0.048 \\
\hline Uric acid, umol/L & $208.00-428.00$ & $252.00(137.25-453.50)$ & $100.00(58.00-161.50)$ & $80.50(63.50-135.25)$ & $125.00(62.75-167.25)$ & 0.018 & 0.020 & 0.050 \\
\hline Creatinine, umol/L & $57.00-111.00$ & $163.50(53.00-544.25)$ & $59.50(47.25-208.75)$ & $77.00(51.75-187.75)$ & $112.00(42.50-241.25)$ & 0.028 & 0.075 & 0.229 \\
\hline eGFR (EPI-Cr) & & $31.38(9.40-102.13)$ & $83.12(27.86-105.47)$ & $73.80(32.25-100.88)$ & $52.98(17.16-101.49)$ & 0.050 & 0.113 & 0.678 \\
\hline Globulin, g/L & $20.00-40.00$ & $33.60(28.45-39.28)$ & $31.95(27.45-39.93)$ & $37.55(34.33-45.70)$ & $35.70(31.78-41.55)$ & 0.857 & 0.039 & 0.591 \\
\hline Albumin, $g / L$ & $40.00-55.00$ & $35.30(31.50-37.35)$ & $36.80(33.45-39.18)$ & $36.30(34.88-40.80)$ & $36.90(33.43-40.68)$ & 0.456 & 0.241 & 0.249 \\
\hline ALT, U/L & $9.00-50.00$ & $17.00(13.50-27.75)$ & $19.00(14.25-41.75)$ & $17.50(14.00-31.50)$ & $24.00(14.75-50.75)$ & 0.525 & 0.884 & 0.387 \\
\hline AST, U/L & $15.00-40.00$ & $32.00(25.75-34.25)$ & $32.50(15.75-97.00)$ & $36.50(26.00-70.25)$ & $36.50(29.25-105.25)$ & 0.600 & 0.132 & 0.178 \\
\hline Total Bilirubin, umol/L & $0.00-26.00$ & $17.70(5.28-42.38)$ & $36.15(14.88-61.23)$ & $23.05(10.58-61.23)$ & $33.25(12.18-80.88)$ & 0.017 & 0.338 & 0.096 \\
\hline Hemoglobin, g/L & $131.00-172.00$ & $92.00(85.50-101.50)$ & $91.50(83.75-101.00)$ & $88.00(80.50-91.75)$ & $78.50(70.75-85.25)$ & 0.704 & 0.116 & 0.029 \\
\hline Hematocrit, \% & $38.00-50.80$ & $27.35(24.70-31.00)$ & $27.70(24.58-31.88)$ & $25.70(23.73-29.18)$ & $22.95(21.23-26.40)$ & 0.960 & 0.454 & 0.051 \\
\hline Blood platelet, x10E9/L & $83.00-303.00$ & $90.00(58.50-120.25)$ & $76.50(64.25-110.00)$ & $77.50(65.75-106.50)$ & $80.00(33.25-133.75)$ & 0.682 & 0.542 & 0.680 \\
\hline Natrium, mmol/L & $137.00-147.00$ & $140.00(137.75-149.50)$ & $139.50(135.00-140.25)$ & $137.50(133.75-139.25)$ & $138.50(136.75-139.25)$ & 0.221 & 0.081 & 0.224 \\
\hline Potassium, mmol/L & $3.50-5.30$ & $4.28(3.99-4.76)$ & $4.40(3.93-4.62)$ & $4.28(4.05-4.43)$ & $4.16(4.09-4.28)$ & 0.907 & 0.562 & 0.493 \\
\hline Total Calcium, mmol/L & $2.11-2.52$ & $2.00(1.84-2.20)$ & $2.15(2.04-2.32)$ & $2.30(2.17-2.39)$ & $2.30(2.20-2.36)$ & 0.069 & 0.006 & 0.007 \\
\hline
\end{tabular}

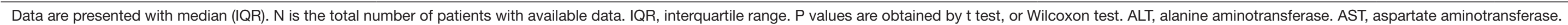

